\title{
Analysis of the Planning Concept of Architectural Genius Loci
}

\author{
Guo-HongLiang ${ }^{1, a}$ \\ ${ }^{1}$ Civil engineering and architecture, Xinxiang college, Xinxiang, Henan, China, 453000 \\ aghlqiuque@126.com
}

Keywords: Residential District; Place; Genius Loci; Planning

\begin{abstract}
The paper adopts the concept, "genius loci", from the field of architecture and regards this concept as a basic point to study the planning of residential districts, taking Emerald Garden located in Nantong City as example and having access to the drawing of planning. Room for exploration of the application of genius loci in the planning of residential areas is quite wide. Genius loci can play more important role in meeting the increasing sense of mental identity.
\end{abstract}

\section{Introduction}

The aim of planning is to understand, comprehend and create a meaningful place for daily life, a true room for a man to have a rest. Hence, the essence of planning is to present genius loci as as to build a significative place. Moore suggests that on landscape design, it can combine the perception and cognition of people to landscape resources with one's experiences and other ways to have humanized design. The paper begins with the essence and meaning of place and genius loci, and has a deep analysis and discussion on the planning of residential areas based on genius loci, summarizing the essential point of the residential districts and the planning of residential areas based on genius loci: it takes Emerald Garden located in Nantong City as example and has access to the drawing of planning. Room for exploration of the application of genius loci in the planning of residential areas is quite wide. Genius loci can play more important role in meeting the increasing sense of mental identity.

\section{Locational Analysis Based on Genius Loci}

The project area of Emerald Garden is flat, covering an area of 33,340 square meters, plot ratio of 1.41 and greening rate of $30 \%$ and the the total number of households being 182. It locates at the intersection of North of Wengfeng Road and South of Haonan Road. It is the core of the old own, Nantong. The surrounding key roads crisscross it, treading through the artery of city. On the south of this project area, there sits Wenfeng Tower (Figure1), a symbol of Nantong city and Wenfeng Park (Figure2) is around, which is a free park. It is built beside Yuan River and its scenery is favorable so it is an important place for citizens to have recreation and hold cultural activities; on the north side, it is Yuannan Road (Figure3). Yuannan Road is the most vital place of Nantong City where people and landscape gather. Although it is not so long, it is the perfect epitome of modern history of Nantong City. Numerous architectures in Republican period are saved on the road: Nantong Museum, Nantong Art Museum and the Former Residence of Zhang Jian, etc.

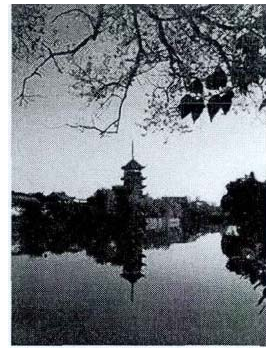

Figure1 Wenfeng Tower

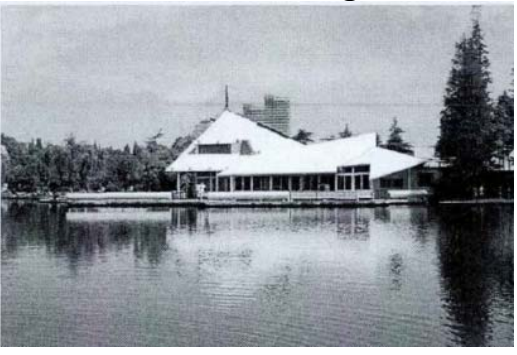

Figure2 Wenfeng Park

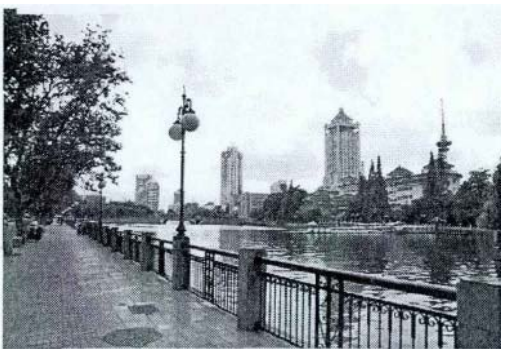

Figure3 Haonan Road

The Extraction and Expression of Genius Loci 
Strong Region Culture:During design, it applies the main design idea---One Emerald Garden, One-half of Jianghai City, presenting Jianghai culture and family culture of Nantong area. To strive for the harmony between the residential environment and the surrounding environment, not being an independent plate, it attempts to combine people's daily life with the residential area. Blend of these life situation and history and culture renders people sense of identity and belonging. The buildings are in gray, fitting in the surrounding environment; according to the traditional folk house, it uses abat-vent with which people are familiar as the architectural style and they face southeast. Cultural activities area in the south of residential community has traditional food center, including refreshments and seafood, etc; residential green area is built into a small space with sense of closure by applying the traditional cultural factors (Figure4 and 5); main entrance tries to be convenient, simple but not exaggerated, and obvious; plants are indigenous but not queer. Flowers that people prefer to appreciate like citrons, orange trees and peonies are ready to be seen.

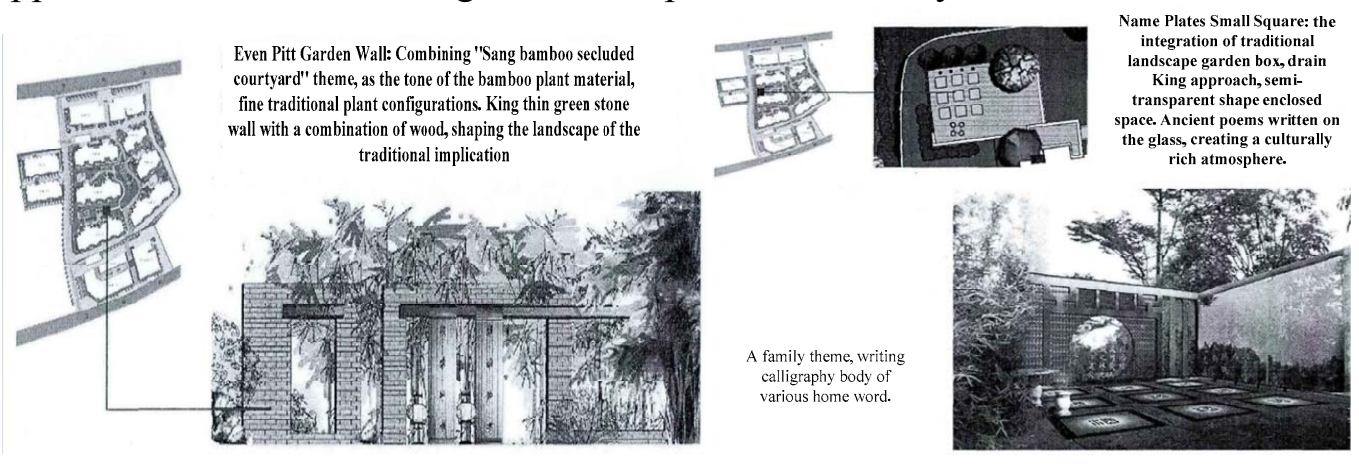

Figure4 Drawing of Intent of Garden Wall Figure5 Effect Drawing of Residential Space

Spatial Experiences of Sense of Belonging:Experience refers to undergoing in person, and tasting by heart. Spatial experience implies the direct experience in the course of undergoing in the fresh, recognizing things and feeling life in spatial environment. In view of path space, it imitates the linear model of the traditional folk house---houses being parallel to and following paths. As far as the spatial inscape is concerned, regional variation connected by the key position of these changeable paths and spatial transformation that sometimes shrinks or enlarge and sometimes narrows or broadens give people sense of experience. It strengthens sense of belonging with this intense experience. On the planning of the residential district, it takes green space as the vital spatial type and focuses on users' sense of experience, creating a most humanized space settlement. Spatial types are divided into gathering space, neighborhood association space, home space and private family privacy by planners in detail. They also use various ways to deal with different spaces. It uses symbolic factors like stonecutting, mat formation, storm lantern and traditional gate pier to build the entrance; gathering space applies plants and walls to create sense of closure; neighborhood space lays stress on comfortable and rich space composition, forming a residential mode imbued with neighborhood and family love and taken green area as the center, which makes dwellers independent from each other but still gives them the best mental distance, ensuring occupiers' sense of territory and belonging. Shown as Figure6.

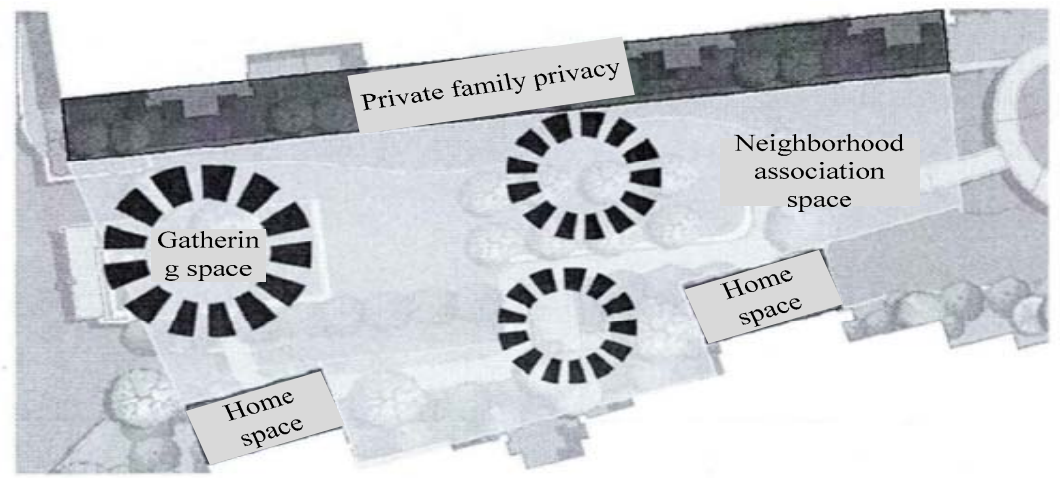

Figure6 Residential Space

Poetic Expression of Landscape:Natural alternations like seasonal change, the rising and setting of the sun, temperature and relative humidity variation, natural scenery, aspect change of plants and 
color fading of building materials, etc are brimming with temporal information, making the microscopic feature of the residential environment keeps changing all the way. Therefore, artistic conception that presents also has dynamic change and people also have varied feeling. On the planning of residential district, it does not make the environment become more new with time past, but it can take mosses on rocks, fading of wood terrace and the growth of wooden objects as those active factors to enhance sense of place. With time pasts, people's sense of place accumulates. Earthen eave is the most common architectural style of traditional folk house building (Figure7). It is not only a functional demand, but also a romantic sign of citizens of Nantong City, showing strong life sentiment of conventional folk house from inside to outside. When design this residential district, it adopts earthen eave and combines modern construction with traditional materials. Furthermore, it applies modern steels on parts playing an important role in supporting. It uses conventional tiles to pave surface, hoping to create a romantic scene that rains drop down from the earthen eave so as to arouse those memories hidden in people's heart (Figure8).
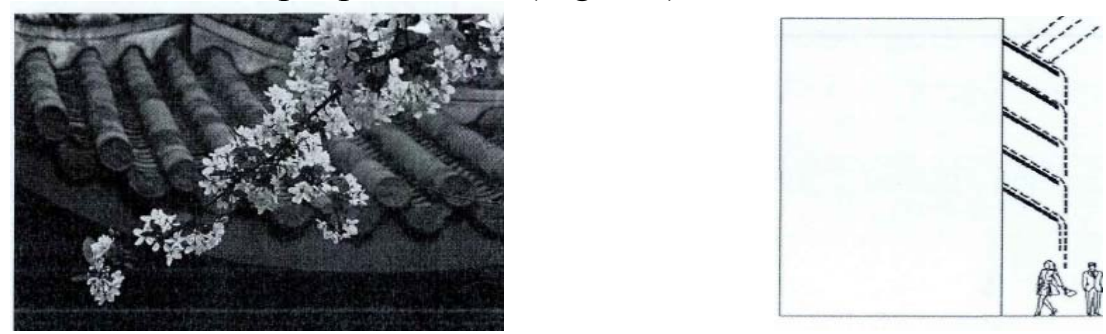

Figure7 Traditional Earthen Eave Figure8 Romantic Scene that Rains Drop down from the Earthen Eave

Details Rich in Regionalism and Interesting:In the corse of designing this residential area, it emphasizes expression of regionalism and interesting of details. When paving the roadway, it gives prior to accessibility and skid resistance. It uses conventional pattern as mat formation, paying attention to diverse visual effects and feelings derived from its material quality, texture and style (Figure9); when dealing with the water, it pursues for richness and interesting (Figure10); it adds characteristic elements of Nantong City like kite, Jianghai, tapis and drum into tables, streetlights, rubbish bins and manhole covers (Figue11).
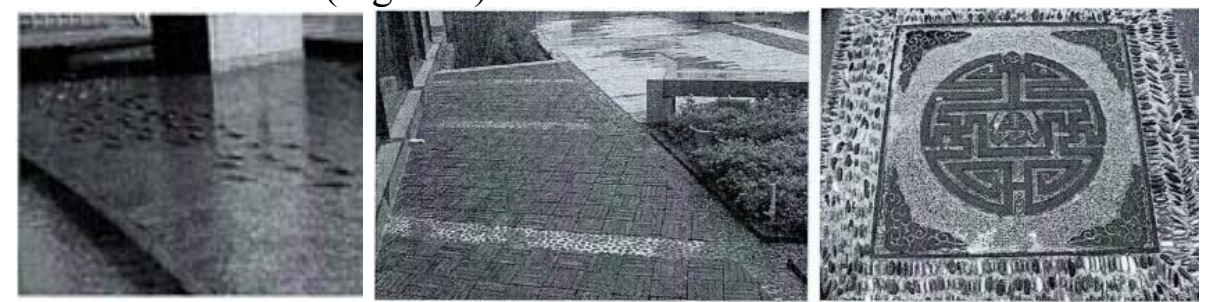

Figure9 Drawing of Intent of Mat Formation; Figure10 Drawing of Intent of the Water;Figure11

Drawing of Intent of tables

\section{Layout of Planning and Project Construction}

Landscape of the whole residential area forms a pattern---three sides, one artery and five spots. One artery refer to the landscape axis leading the residential district. The axis combines the south and the north of the internal part, decorated by stones and water, wood terrace in the water and recreation site in the woods. This axis links "five spots", that is, Fang'e Park, Shiqu Park, Lianbi Park, Taidi Park and Cuiya Park. These five spots locate within green space, offering dwellers pleasant scenes and having a certain guidance quality.

Landscape channel mainly uses natural materials like gray tiles, slabstones, pebbles and boardwalks. It is simple and unadorned, highly harmonious with the surrounding environment, highlighting cozy and relaxed walking experience. Carving is also applied in footpath and landscape channel. To seek for auspiciousness is the common wish for people. Propitious patterns render the road a highly appreciation and sense of culture, and their pleasant implied meaning is consistent with people's wishes. Chinese traditional auspicious patterns like “ Xi (magpie), Lu (deer), Feng (bee), Hou (monkey)" and patterns with the lingering charm of Nantong City like Jianghai, wind and long 
bridge are all popular spectator patterns. They also deliver people's wishes for being safe. "Cuiya Park" lies in the center of the entrance of the south residential district, namely, in the left of the landscape channel or between the No.5 building and the No.7 building. It applies a method---"to restrain before development" to create a simple but meaningful space with spatial opening and closing process. Meanwhile, it uses traditional courtyard-based landscape plants like bamboo and plum blossom. In the courtyard, there are tables beside the pool in which gardenias are planted. During summer, their aroma fill people's nostrils; on the floor, there are four auspicious bluestones with Chinese traditional tortoiseshell pattern, swastika pattern, fret and fangsheng pattern. We can enjoy the tranquility and humanistic care of the courtyard-based landscape space; in the back of the yard, there stands a medicinal citron with beautiful tree figure and filled with fruits, which become a focal point. Through the fresh and simple wood path, you can see bamboo, osmanthus, hydrangea and lagerstroemia indica play separating role as they have founded the "wall", covering the external space ambiguously. It is a courtyard that highlights spatial integration. As the effect drawing shown in Figure12.

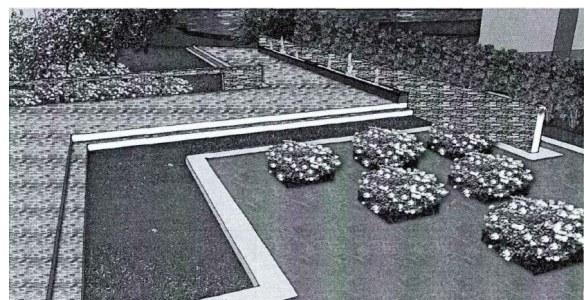

Figure12 Effect Drawing of Cuiya Park

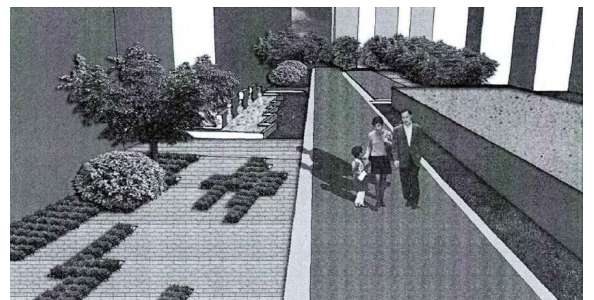

Figure13 Effect Drawing of Fangfu Park

To design a straight path linking the west and the east together that has specific spatial guidance quality. It adopts all kinds of ways for space processing. Using plants for cover to meet people's demands for privacy and having stone lamp on the entrance to call people's attention. Mat formation with small water pattern and embedded strips with grass shape changes the rhyme of the straight path so people walking on it can not feel dull. Effect drawing and graphic model of Fangfu Park are shown as Figure13 and Figure4.

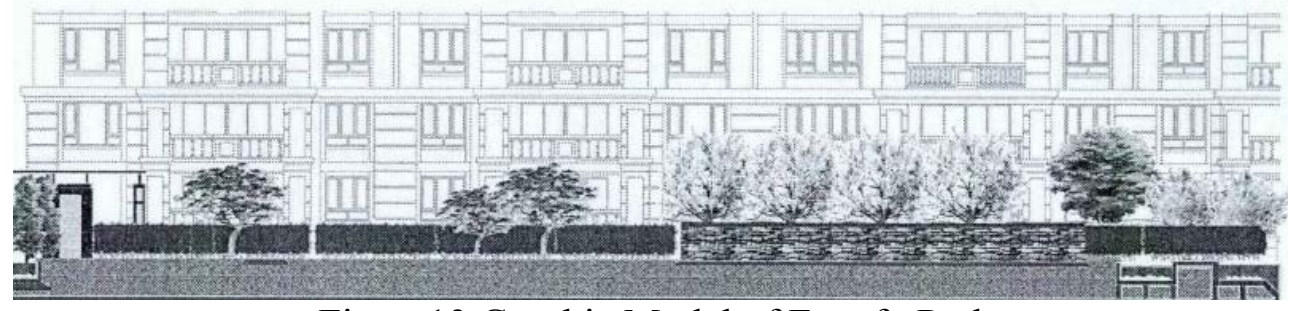

Figure13 Graphic Model of Fangfu Park

\section{Conclusion}

With further study, we gradually find that place and spirit not only involves accretion of regional material culture, but also include a series of fields like spiritual culture, aesthetic and value orientation extract design methods of the local genius loci on the basis of natural environment, historical culture, customs and folkways and market conditions. It displays the genius loci with general layout, partial design, architectural design and flat design. Moreover, it shows the planning results in drawing form.

\section{Acknowledgements}

The national natural science fund, 51208329)

\section{References}

[1] Chen Chen. The Impact of "Nature" Thought on Design Art in Daoism[J]. Art and Design ,2007, 4 (1): 8-10. 
[2] Chen Weiyue, Luo Yanyun. The Application Origin and Development of Bamboo in Chinese Living Environment[J]. Northern Horticulture, 2007,(3):83-85.

[3] Cheng Dong. Return to the Spirit of Place[J]. Chinese and Overseas Architecture, 2011,(5):17-20.

[4] Gao Bei. The Meaning of Place An Actual Topic[J]. Fujian Architecture, 2010,(4) :92-93.

[5] Yong Liang. From Environment of Place to Spirit of Place---Meditation Coming from the Design of Community Service Building in Siming District[J]. Fujian Architecture, 2010, (2): 29-36.

[6] Su Xiaoyi. Landscape Design of Residential District[M]. Beijing: China Architecture and Building Press, 2010.

[7] Tian Baojiang. Study on Level Design of the External Space of the Residential District[J]. Urbanism and Architecture, 2011,(3) :12-16.

[8] Wang Yi. Study on the Expression of Genius Loci in Urban Landscape Design[D]. Master's Thesis of Shenyang Jianzhu University, 2011.

[9] Wu Wei. Brief Study on Spirit of Place of Garden[D]. Master's Thesis of Huazhong Agricultural University, 2011.

[10]Wang Na, Yang Maochuang. Study on the Application of Chinese Traditional Elements in Modern Interior Design[J]. Shanxi Architecture, 2009,10(5):217-218. 